\title{
Adjuvant Chemotherapy for Bladder Cancer: One Step Forward, two Steps Back
}

\author{
Laeeq Malik ${ }^{1}$ \\ ${ }^{1}$ Institute for Drug Development, Cancer Therapy and Research Center, University of Texas Health Science \\ Center at San Antonio, San Antonio, Texas, USA \\ Correspondence: Laeeq Malik, MD, FRACP, Institute for Drug Development, Cancer Therapy and Research \\ Center, University of Texas Health Science Center at San Antonio, San Antonio,Texas, USA. Tel: \\ 1-210-450-5947.E-mail: Malikl@uthscsa.edu
}

\author{
Received: October 14, 2014 Accepted: November 5, 2014 Online Published: November 26, 2014 \\ doi:10.5539/cco.v4n1p14 \\ URL: http://dx.doi.org/10.5539/cco.v4n1p14
}

\begin{abstract}
Bladder cancer is a common and lethal disease. Optimal treatment for high risk patients includes local and systemic therapy (neoadjuvant or adjuvant chemotherapy). It has not been demonstrated that adjuvant chemotherapy after cystectomy prolongs survival. Evidence regarding the role of adjuvant chemotherapy is conflicting and further randomized data are needed. This publication discusses the past, present, and future of adjuvant treatment in bladder cancer. It summarizes prior adjuvant trials, with a focus on long-awaited results from a large phase III trial and the future landscape.
\end{abstract}

Keywords: bladder cancer, chemotherapy, adjuvant

\section{Introduction}

Muscle-invasive bladder cancer is an aggressive tumor that was associated with a median survival of 22 months in the 1980s (Babiker, Shearer, \& Chilvers, 1989). Patients with muscle-invasive disease have a 50 to $65 \%$ overall survival rate in the modern era (C. N. Sternberg et al., 2007). For many years, neoadjuvant chemotherapy and surgery have been the mainstay of muscle-invasive cancer treatment. Unfortunately, several studies have shown that neoadjuvant chemotherapies are underutilized in the management of muscle-invasive bladder cancer (David, Milowsky, Ritchey, Carroll, \& Nanus, 2007). Hence, patients often receive adjuvant chemotherapy following radical cystectomy. Although, results from the neoadjuvant studies are often extrapolated to the adjuvant setting, there is only low quality evidence to support the use of adjuvant chemotherapy. The purpose of this paper is to provide a critical overview of various adjuvant studies that have been conducted to evaluate the role of adjuvant chemotherapy with a particular focus on long-awaited results from a large randomized Phase III trial.

\section{Discussion}

To address this issue, Sternberg et al. recently reported long term results from trial 30994 of the European Organisation for Research and Treatment of Cancer (EORTC)(Cora N. Sternberg et al., 2014). In this large randomized trial of adjuvant chemotherapy, 284 patients from 63 sites with pT3 or T4 and/or N+ M0 bladder cancer were assigned immediate or deferred chemotherapy after radical cystectomy. Patients were stratified according to the treatment center, tumor stage and lymph node status. This study was designed to demonstrate an improvement in 5-year survival rate from $35 \%$ for the deferred group to $42 \%$ for the treatment group. Overall survival, the primary endpoint, appeared to improve with immediate chemotherapy based on a median value of 6.75 years, as compared with 4.6 years with the deferred approach. Although, this difference resulted in a $22 \%$ reduction in the relative risk of death with adjuvant chemotherapy, the improvement failed to reach statistical significance (HR 0.78, p=0.13). Progression-free survival, a secondary endpoint, showed a significant improvement with median values of 2.92 years (immediate chemotherapy) versus 0.93 years (deferred chemotherapy) $(\mathrm{p}<0.0001)$. The progression-free survival benefit was seen across all subgroups. Immediate adjuvant chemotherapy failed to improve an overall survival in this trial, these data raise some concerns if adjuvant chemotherapy after radical cystectomy is useful at all.

To answer that question thoughtfully, we must dig a little deeper and put this study in perspective. The available 
data supporting an adjuvant approach are less convincing as historically adjuvant bladder cancer trials have suffered from poor accrual and methodological flaws. Over the years, several randomized trials have investigated a potential benefit of adjuvant chemotherapy in the bladder cancer of which the largest trial accrued 194 patients. The Italian study of adjuvant chemotherapy (gemcitabine, cisplatin) involving patients with pT2-4, N0-2 bladder carcinoma was originally designed and powered to show an improvement in 2-year overall survival by $10 \%$ (Cognetti et al., 2012). The primary endpoint was overall survival and the secondary endpoints included disease-free survival, toxicity and quality of life. This trial was closed early due to low enrollment. There was no difference in either overall survival or disease-free survival compared to observation. Clearly, this study was underpowered due to poor accrual to show the impact of treatment on either endpoint. Although, a Spanish oncology group trial that used adjuvant chemotherapy with four cycles of paclitaxel, gemcitabine and cisplatin or observation, reported in 2010 that the adjuvant chemotherapy was beneficial, given that there was an increase in 5 -year overall survival in the treated group versus observation group $(60 \% v 30 \%$, respectively) (Paz-Ares et al., 2010). However, the benefit of adjuvant chemotherapy is not clear as this trial was also terminated after only 142 patients were enrolled (because of poor accrual), and the power for firm conclusions is limited. A number of other smaller inconclusive adjuvant clinical trials are listed in Table 1.

Table 1. Comparison of randomized adjuvant chemotherapy trials

\begin{tabular}{|c|c|c|c|c|c|c|}
\hline Study & $\begin{array}{l}\text { Targeted } \\
\text { accrual }\end{array}$ & $\begin{array}{l}\text { Actual } \\
\text { accrual }\end{array}$ & Chemotherapy & $\begin{array}{l}\text { Survival (5-year OS or } \\
\text { median OS) }\end{array}$ & $\begin{array}{l}\text { Hazard ratio } \\
\text { for survival }\end{array}$ & P-value \\
\hline $\begin{array}{l}\text { Sternberg et al. (Cora } \\
\text { N. Sternberg et al., } \\
2014 \text { ) }\end{array}$ & 1384 & 284 & $\begin{array}{l}\text { GC/HD-MVAC } \\
\text { /MVAC } \\
\text { Observation }\end{array}$ & $\begin{array}{l}81.6 \mathrm{mo} \\
55.2 \mathrm{mo}\end{array}$ & 0.78 & 0.13 \\
\hline $\begin{array}{l}\text { SOGUG } \\
\text { (Paz-Ares et al., } \\
2010)\end{array}$ & 340 & 142 & $\begin{array}{l}\text { PCG } \\
\text { Observation }\end{array}$ & $\begin{array}{l}\mathrm{NR} \\
26 \mathrm{mo}\end{array}$ & 0.44 & $<0.0009$ \\
\hline $\begin{array}{lll}\text { Cognetti } & \text { et } & \text { al. } \\
(\text { Cognetti } & \text { et al., } \\
2012) & & \end{array}$ & 610 & 194 & $\begin{array}{l}\text { GC } \\
\text { Observation }\end{array}$ & $\begin{array}{l}43.4 \% \\
53.7 \%\end{array}$ & 1.29 & 0.24 \\
\hline $\begin{array}{l}\text { Freiha et al. (Freiha, } \\
\text { Reese, \& Torti, } \\
\text { 1996) }\end{array}$ & - & 55 & $\begin{array}{l}\text { CMV } \\
\text { Observation }\end{array}$ & $\begin{array}{l}63 \mathrm{mo} \\
36 \mathrm{mo}\end{array}$ & NG & 0.32 \\
\hline $\begin{array}{l}\text { Skinner et al. } \\
\text { (Skinner et al., 1991) }\end{array}$ & - & 91 & $\begin{array}{l}\text { CDC } \\
\text { Observation }\end{array}$ & $\begin{array}{l}51.6 \mathrm{mo} \\
28.8 \mathrm{mo}\end{array}$ & NG & 0.0062 \\
\hline $\begin{array}{l}\text { Studer et al. (Studer } \\
\text { et al., 1994) }\end{array}$ & - & 77 & $\begin{array}{l}\text { C } \\
\text { Observation }\end{array}$ & $\begin{array}{l}57 \% \\
54 \%\end{array}$ & NG & 0.65 \\
\hline $\begin{array}{l}\text { Stockle et al. } \\
\text { (Stockle et al., 1995) }\end{array}$ & - & 49 & $\begin{array}{l}\text { MVAC/ MVEC } \\
\text { Observation }\end{array}$ & $\begin{array}{l}\text { Stopped early due to a } \\
\text { significant increase in } \\
\text { disease free survival for } \\
\text { adjuvant therapy }\end{array}$ & - & - \\
\hline $\begin{array}{lll}\text { Lehman et al. } & \text { al. } \\
\text { (Lehmann et al., } \\
\text { 2005) }\end{array}$ & - & 327 & $\begin{array}{l}\text { CM } \\
\text { MVEC }\end{array}$ & $\begin{array}{l}57.3 \mathrm{mo} \\
63.3 \mathrm{mo}\end{array}$ & 1.13 & 0.0528 \\
\hline
\end{tabular}

Abbreviations: OS- overall survival; mo- months; GC- gemcitabine, cisplatin; NR- not reached; NG- not given; PCG- paclitaxel, cisplatin, gemcitabine; C-cisplatin; CMV- cisplatin, methotrexate, vinblastine; MVACmethotrexate, vinblastine, cisplatin, doxorubicin; CDC- cisplatin, doxorubicin, cyclophosphamide; MVECmethotrexate, vinblastine, cisplatin, epirubicin; CM- cisplatin, methotrexate.

In the absence of conclusive randomized trial results, many retrospective reviews and meta-analysis have been conducted to further investigate a potential benefit of adjuvant chemotherapy in the bladder cancer. The largest review was undertaken by Svatek et al. and included a total of 3947 patients from 11 different institutions 
(23.9\% of whom received adjuvant chemotherapy) (Svatek et al., 2010). Adjuvant chemotherapy was found to be independently associated with an improved survival. With a median follow-up of 32 months, administration of adjuvant chemotherapy resulted in a significant survival benefit in patients at highest risk of death from disease (HR $0.75 ; \mathrm{P}=0.002$ ). The patients at highest risk for disease progression were defined by the pathologic stage of their disease and the extent of nodal involvement. A meta-analysis was conducted in 2005 to address this important question ("Adjuvant chemotherapy in invasive bladder cancer: a systematic review and meta-analysis of individual patient data Advanced Bladder Cancer (ABC) Meta-analysis Collaboration," 2005). Individual patient data of 491 subjects from six randomized controlled trials were pooled and reviewed. This demonstrated a $25 \%$ reduction in the relative risk of death with the use of adjuvant cisplatin-based chemotherapy when compared to control. The overall hazard ratio of 0.75 was conventionally significant $(\mathrm{P}=0.019)$, and equivalent to an absolute improvement in survival of $9 \%$ at 3 years. Although a significant difference in survival was observed favoring chemotherapy compared with observation. The results of this meta-analysis are limited and insufficient to be conclusive to support the routine use of adjuvant cisplatin-chemotherapy because of relatively low number of patients and the methodological concerns. A recent systematic review of adjuvant trials in muscle-invasive bladder cancer was also unable to demonstrate a survival benefit (Meeks et al., 2012).

The data presented above in support of adjuvant chemotherapy in bladder cancer is flawed due to methodological concerns related to the individual trial, limited sample sizes, and a significant variability in number of cycles/ doses of chemotherapy regimen that was used. It was anticipated that the EORTC trial may put this issue to rest, if the investigators were able to enroll 1344 patients (Cora N. Sternberg et al., 2014). The study was carefully designed to increase an accrual by offering flexibility with a choice of chemotherapy, trial design and eligibility criteria. Despite the heroic efforts, this study was closed after 284 patients due to poor accrual rate. Contrary to the previous randomized studies, an exploratory analysis for overall survival demonstrated that the adjuvant chemotherapy may prolong survival in node negative patients and not in node positive patients (HR of 0.39 and 0.90 respectively). It is not clear if this difference is real, spurious or related to disease biology as the node negative patients in this study only constituted $30 \%$ of study population.

\subsection{How Would These Results Impact the Way We Treat Patients?}

Neoadjuvant chemotherapy is the standard of care for muscle-invasive bladder cancer. Clinicians who have patients with bladder cancer should choose neoadjuvant approach if they want the treatment that is most likely to benefit their patients. Unfortunately, the question of whether adjuvant chemotherapy in bladder cancer following radical cystectomy improves survival still remains open. There is still no level I evidence to support adjuvant chemotherapy in bladder cancer. Despite limited data, there are strong bases for the use of adjuvant chemotherapy. There are several reasons for this. The argument for use of adjuvant chemotherapy is based on the inaccuracies of clinical staging, that can sometimes make the identification of patients destined to benefit from neoadjuvant approach difficult. There is also a concern that if patients do not respond to neoadjuvant treatment, the delay in definitive therapy may compromise a possibility of cure. Hence, when considering adjuvant treatment, correct patient selection is very important. Some patients with bladder cancer may have a substantial relapse risk and therefore might benefit from adjuvant treatment. On the other hand, unnecessary treatment may expose patients to unwanted side effects and this risk must be minimized.

\subsection{How Would These Findings Impact The Future Bladder Cancer Research?}

Ideally we need adequately powered, randomized trials with a sufficient follow-up demonstrating survival benefits with adjuvant chemotherapy for patients with muscle-invasive disease. The EORTC as well as other studies were closed early due to poor accrual. The poor accrual to these adjuvant trials could be due to a bias (physician or patient) against observation alone. While adjuvant clinical trials did not demonstrate a survival difference, they showed that its difficult to conduct large, multicenter, adjuvant clinical trials in bladder cancer. It is possible that the old era of adjuvant chemotherapy trials is over as neoadjuvant trials provide the platform for advancing the field. Overall, it seems that the landscape of adjuvant clinical trials in bladder cancer is not likely to expand and diversify further in the years to come. Furthermore, results of ongoing Phase III studies assessing the role of adjuvant chemotherapy would unlikely resolve this issue (ClinicalTrials.gov identifier: NCT01812369, NCT02074189, NCT01734798). Considering the upcomming immunotherapy advances in metastatic disease, the next few years may see growing interest in neoadjuvant clinical trials. The success of future clinical trials in both neoadjuvant and adjuvant settings would largely depend upon patient ennrolment, in addition to the new innovative drug development strategies, new regulatory approaches, enhanced collaboration between cooperative groups, and biomarker-driven clinical trial designs. A better understanding of tumor biology may provide new drug-able targets that are specific to the cancer cell or its environment. The incorporation of genomic information may hold promise to improve drug development process in bladder cancer. The inability to identify 
critical targets involved in bladder cancer cell growth and survival is one of the reasons that we are not witnessing a tremendous progress. Previous individual patient data metanalysis was unable to prove the value of adjuvant chemotherapy ("Adjuvant chemotherapy in invasive bladder cancer: a systematic review and meta-analysis of individual patient data Advanced Bladder Cancer (ABC) Meta-analysis Collaboration," 2005). More answers will only become available if we perform another meta analysis using patient level data. Patients who do not receive neoadjuvant therapy should be considered for enrollment onto adjuvant clinical trials if available.

\section{Conclusions}

We do need treatments that improve survival of patients with bladder cancer, but if we refuse to build on the small steps that have been made in bladder cancer treatment, we will not improve overall survival without major breakthroughs. Investigators should design studies that build on the available findings admittedly inadequate while searching for more effective approaches. New strategies are therefore required, not only with regard to the biological and pharmacological approaches to relapse risk reduction in bladder cancer but also with regard to trial design and resource allocation. The future adjuvant clinical trial landscape in bladder cancer will therefore be informed by the increasing understanding of the molecular pathology of bladder cancer and by the emerging clinical evidence for treatment of metastatic disease. We need to move forward, but just because we have not progressed far enough, we should not move back.

\section{Funding}

None.

\section{Conflict of Interest}

None.

\section{References}

Adjuvant chemotherapy in invasive bladder cancer: a systematic review and meta-analysis of individual patient data Advanced Bladder Cancer (ABC) Meta-analysis Collaboration. (2005). European Urology, 48(2), 189-199; discussion 199-201. http://dx.doi.org/10.1016/j.eururo.2005.04.005

Babiker, A., Shearer, R. J., \& Chilvers, C. E. (1989). Prognostic factors in a T3 bladder cancer trial. Co-operative Urological Cancer Group. British Journal of Cancer, 59(3), 441-444.

Cognetti, F., Ruggeri, E. M., Felici, A., Gallucci, M., Muto, G., Pollera, C. F., . . Boccardo, F. (2012). Adjuvant chemotherapy with cisplatin and gemcitabine versus chemotherapy at relapse in patients with muscle-invasive bladder cancer submitted to radical cystectomy: an Italian, multicenter, randomized phase III trial. Annals of Oncology, 23(3), 695-700. http://dx.doi.org/10.1093/annonc/mdr354

David, K. A., Milowsky, M. I., Ritchey, J., Carroll, P. R., \& Nanus, D. M. (2007). Low incidence of perioperative chemotherapy for stage III bladder cancer 1998 to 2003: a report from the National Cancer Data Base. Journal of Urology, 178(2), 451-454. http://dx.doi.org/10.1016/j.juro.2007.03.101

Freiha, F., Reese, J., \& Torti, F. M. (1996). A randomized trial of radical cystectomy versus radical cystectomy plus cisplatin, vinblastine and methotrexate chemotherapy for muscle invasive bladder cancer. Journal of Urology, 155(2), 495-499; discussion 499-500.

Lehmann, J., Retz, M., Wiemers, C., Beck, J., Thuroff, J., Weining, C., . . . Stockle, M. (2005). Adjuvant cisplatin plus methotrexate versus methotrexate, vinblastine, epirubicin, and cisplatin in locally advanced bladder cancer: results of a randomized, multicenter, phase III trial (AUO-AB 05/95). Journal of Clinical Oncology, 23(22), 4963-4974. http://dx.doi.org/10.1200/jco.2005.11.094

Meeks, J. J., Bellmunt, J., Bochner, B. H., Clarke, N. W., Daneshmand, S., Galsky, M. D., . . Sonpavde, G. (2012). A systematic review of neoadjuvant and adjuvant chemotherapy for muscle-invasive bladder cancer. European Urology, 62(3), 523-533. http://dx.doi.org/10.1016/j.eururo.2012.05.048

Paz-Ares, L. G., Solsona, E., Esteban, E., Saez, A., Gonzalez-Larriba, J., Anton, A., . . Bellmunt, J. (2010). Randomized phase III trial comparing adjuvant paclitaxel/gemcitabine/cisplatin (PGC) to observation in patients with resected invasive bladder cancer: Results of the Spanish Oncology Genitourinary Group (SOGUG) 99/01 study Journal of Clinical Oncology,Vol 28, No 18_suppl (June 20 Supplement): abstract \#LBA4518

Skinner, D. G., Daniels, J. R., Russell, C. A., Lieskovsky, G., Boyd, S. D., Nichols, P., . . Groshen, S. (1991). The role of adjuvant chemotherapy following cystectomy for invasive bladder cancer: a prospective 
comparative trial. Journal of Urology, 145(3), 459-464; discussion 464-457.

Sternberg, C. N., Donat, S. M., Bellmunt, J., Millikan, R. E., Stadler, W., De Mulder, P., . . . Soloway, M. S. (2007). Chemotherapy for bladder cancer: treatment guidelines for neoadjuvant chemotherapy, bladder preservation, adjuvant chemotherapy, and metastatic cancer. Urology, 69(1 Suppl), 62-79. http://dx.doi.org/10.1016/j.urology.2006.10.041

Sternberg, C. N., Skoneczna, I. A., Kerst, J. M., Fossa, S. D., Albers, P., Agerbaek, M., . . Sylvester, R. (2014). Final results of EORTC intergroup randomized phase III trial comparing immediate versus deferred chemotherapy after radical cystectomy in patients with pT3T4 and/or N+ M0 transitional cell carcinoma (TCC) of the bladder. J Clin Oncol 32:5s, 2014 (suppl; abstr 4500).

Stockle, M., Meyenburg, W., Wellek, S., Voges, G. E., Rossmann, M., Gertenbach, U., . . . Hohenfellner, R. (1995). Adjuvant polychemotherapy of nonorgan-confined bladder cancer after radical cystectomy revisited: long-term results of a controlled prospective study and further clinical experience. Journal of Urology, 153(1), 47-52. http://dx.doi.org/10.1097/00005392-199501000-00019

Studer, U. E., Bacchi, M., Biedermann, C., Jaeger, P., Kraft, R., Mazzucchelli, L., . . . Sonntag, R. W. (1994). Adjuvant cisplatin chemotherapy following cystectomy for bladder cancer: results of a prospective randomized trial. Journal of Urology, 152(1), 81-84.

Svatek, R. S., Shariat, S. F., Lasky, R. E., Skinner, E. C., Novara, G., Lerner, S. P., . . Dinney, C. P. (2010). The effectiveness of off-protocol adjuvant chemotherapy for patients with urothelial carcinoma of the urinary bladder. Clinical Cancer Research, 16(17), 4461-4467. http://dx.doi.org/10.1158/1078-0432.ccr-10-0457

\section{Copyrights}

Copyright for this article is retained by the author(s), with first publication rights granted to the journal.

This is an open-access article distributed under the terms and conditions of the Creative Commons Attribution license (http://creativecommons.org/licenses/by/3.0/). 